\title{
First female cardiac surgeon
}

Azat K. Turgunov 1,2

\author{
${ }^{1}$ Scientific Research Institute of Heart Surgery and Organ Transplantation, Bishkek, Kyrgyzstan \\ ${ }^{2}$ International Higher School of Medicine, Bishkek, Kyrgyzstan
}

\begin{abstract}
For a long time, medicine was the prerogative of men, and women were not allowed to this area. And despite the prohibitions and moral values of those times, women left a mark in the history of medicine.
\end{abstract}

Key words: women, medicine, history, cardiac surgery

(Heart Vessels Transplant 2021; 5: doi: 10.24969/hvt.2020.266)

Medicine has gone through many eras, and the role of certain people has changed the course of history. For example, Aristotle (384-322 BC) is recognized by the earliest observations of normal cardiovascular function, describing fetal pulsation in a chicken embryo. Also, Claudius Galen noted the structural differences between arteries and veins $(1,2)$, but did not understand how blood circulates. Further William Harvey disproved the sacred theories of Galen and suggested the existence of capillaries that connect the arterial and venous systems (3), but was not able to demonstrate a capillary network due to the lack of a microscope at those times.

Along with technical difficulties, there were also moral difficulties, one of which is the prohibition of providing medical treatment by women. However in spite of these obstacles, the first woman physician in our era was Margaret Ann Bulkley (Fig. 1), as in the legend of the Athenian woman Agenodice who lived in the 3rd century BC (4), who for the sake of medicine lived her whole life until her death under the guise of a man, as David Barry. Despite the bans, she entered the medical school in Edinburgh, and served as army surgeon reaching rank of general. She is also known for performance of first C-section with both mother and child survived (5).

In 1849, Elizabeth Blackwell became the first woman to receive a medical degree in the United States. She was constantly oppressed because women had no place in medicine. However, she graduated with honors and opened a waiting room for patients in her own home, and later a clinic for poor women and children, created a medical college for women, a sanitary commission (6).

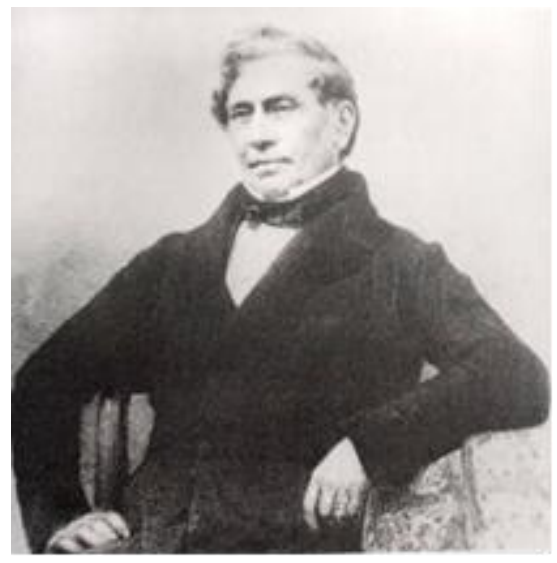

Figure 1. Margaret Ann Bulkley (James Barry) - the first woman physician - military surgeon in modern era

(Photograph is re-published under CC.BY. SA -3.0 license permitting republication with citing source from en.wikipedia.org/wiki/James_Barry_(surgeon)

Address for Correspondence: Azat K.Turgunov, Scientific Research Institute of Heart Surgery and Organ Transplantation, Togolok Moldo Str 3/1, Bishkek, Kyrgyzstan Email: Azaturgunov@gmail.com

Received: 10.08.2021 Revised: 23.08.2021 Accepted: 24.03.2021 


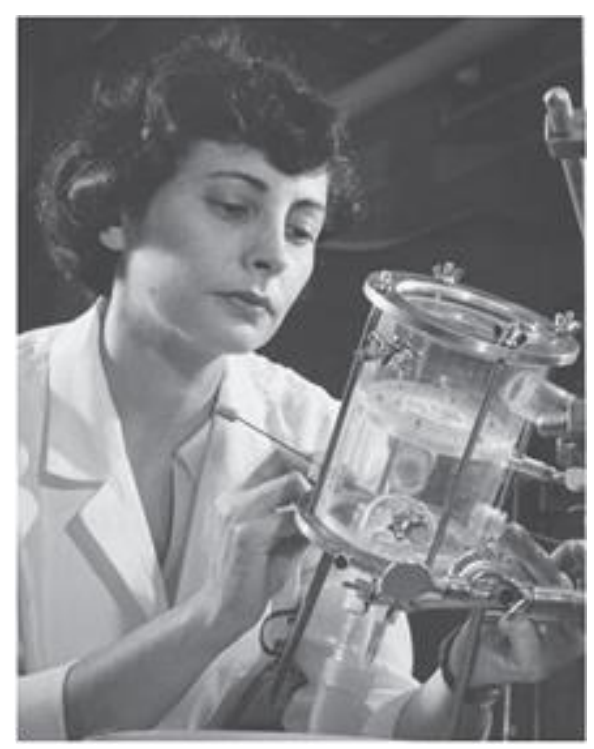

Figure 2. Nina Starr-Braunwald - a first woman heart surgeon (Reproduced under CC BY-SA 4.0 license from Wikipedia - https://www.wikiwand.com /en/Nina_Starr_Braunwald)

From that moment on, women replenished in various fields of medicine.

A century later, Dr. Nina Starr Braunwald was born in Brooklyn, New York $(7,8)$. From an early age, she was interested in the cultivation of Paramecium spp, which became the reason to join the American Society of Microscopy Amateurs (9). After graduating from college, she had ambitious goals to become a physician, and later a surgeon, and entered New York University Medical School and began an internship at the hospital in 1952, officially becoming the first female intern in the department of general surgery (Fig. 2). During her studies, she received her master's degree, completing her graduate studies with Dr.

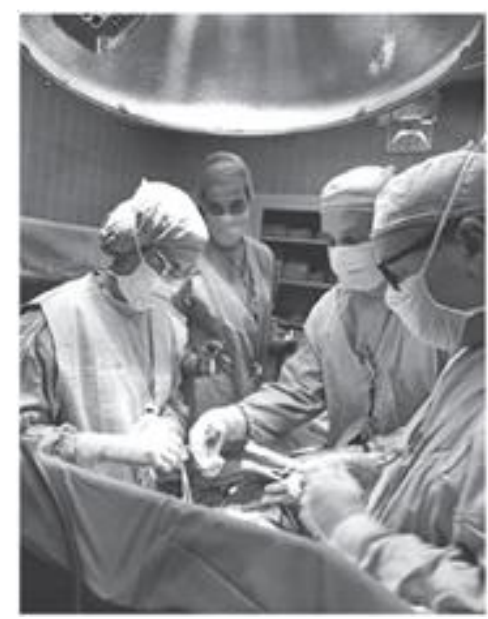

Charles Hufnagel, a pioneer in cardiac surgery whose research led to the invention of the first artificial valve at Georgetown University (10). She then completed her residency in general surgery, becoming the Chief Resident at Georgetown University Medical Center. In 1958, she was offered a 2-year fellowship in cardiothoracic surgery to Dr. Andrew Morrow, who was the head of the surgery clinic at the National Institutes of Health (NIH) in Bethesda, Maryland. Under Morrow's continued support and guidance, she began a career in academic cardiothoracic surgery and became the first woman to be certified by the American Board of Thoracic Surgery in 1963 (11).

Figure 3. First mitral valve replacement by Nina Starr Braunwald

(Photograph courtesy of the Office of History, National Institute of Health and the National Library of Medicine.) 
On March 11, 1960, under the direction of Dr. Andrew Morrow, she performed the world's first successful mitral valve replacement surgery on a 44-year-old woman, who had end-stage heart failure by implanting the Braunwald-Morrow valve-a novel prosthetic heart valve that she had designed and that was made of flexible polyurethane flaps for valve leaflets and Teflon ribbons for the chordae tendinae (Fig. 3). The patient made a full recovery and was discharged from the hospital on May 22, 1960. Unfortunately, she died 4 months later due to an arrhythmia. Her interest in developing new valve prostheses went on with the development of the Braunwald-Cutter valve, a cloth-covered mechanical valve that had been successfully implanted in thousands of patients since the 1960s and throughout the 1970s. (11)

In 1965, she was promoted to Deputy Chief at the NIH and continued to conduct top-notch research in cardiac surgery. She was then appointed as Associate Professor of Surgery at the Cardiothoracic Department of the new University of California in 1968. She, therefore, moved to San Diego with her husband, the world-renown cardiologist Dr. Eugene Braunwald.

Dr. Starr Braunwald's interests went beyond valvular disease, and she also made incredible contributions to the surgical and scientific development of congenital heart disease. In 1972, Nina and Eugene Braunwald moved permanently to Boston, where Dr. Eugene Braunwald was called to lead the Department of Internal Medicine at Harvard University, which is traditionally called the Department of Theory and Practice of Medicine. Nina Braunwald was recruited at Children's Hospital Medical Center, which was affiliated with Harvard Medical School, where she initially participated in surgical procedures to treat ventricular septal defects (12).

Dr. Starr Braunwald died of breast cancer on August 5, 1992. Her husband, her friends and colleagues decided to honor her memory and her unparalleled commitment to cardiac surgery by instituting awards on her behalf for female cardiothoracic surgeons. The Nina Starr Braunwald Prize is awarded in two categories: Resident Braunwald Fellowship for Interns and Braunwald Research Grants, Career Development Awards and Research Awards for Academic Surgeons (13).

Despite all the difficulties on the way to becoming a heart surgeon, Nina Starr Braunwald as a person and as a woman proved to everyone that you can achieve your purpose with desire and determination. Thus, she left her mark on the history of cardiac surgery.
Peer-review: External and internal
Conflict of interest: None to declare

Authorship: A.K.T

Acknowledgments and funding: None to declare

\section{References}

1. Osler W. The evolution of modern medicine. Yale: Yale University Press; 1921.

2. Thiene $G$. The discovery of circulation and the origin of modern medicine during the Italian Renaissance. Cardiol Young 1996; 6: 109-19.

3. Harvey W. Exercitatio anatomica de motu cordis et sanguinis in animalibus. Francfort: W. Fitzer; 1628.

4. Mark JJ Women in ancient Egypt. World History Encyclopedia. Available at: URL www.worldhistory.org/article/623/women-in-ancient -egypt/

5. Pain S. The military surgeon who hid his female history. Available at: URL: www.newscientist.com (3 March 2008).

6. Elizabeth Blackwell, M.D. Br Med J 1910; 1: 1523-4.

7.Singh S, DiGiacomom JC, Angus LDG. "It Will Work": The story of Nina Starr Braunwald and the first successful mitral valve replacement. Ann Thorac Surg 2021; April 24, 2021

8. Tesler UF. A History of cardiac surgery: an adventurous voyage from antiquity to the artificial heart by Ugo Filippo Tesler. Cambridge Scholars Publishing: 2020; pp.542.

9. Benfield JR, Kohman L. Mentorship, women thoracic surgeons, and the thoracic surgery foundation for research and education. Ann Thorac Surg 2004; 78: 1135-6.

10. DeWall RA, Qasim N, Carr L Evolution of mechanical heart valves. Ann Thorac Surg 2000; 69: 1612- 21.

11. Sabharwal N, Dev H, Smail H, McGiffin DC, Saxena P. Nina Braunwald: a female pioneer in cardiac surgery. Tex Heart Inst J 2017; 44: 96- 100.

12. Braunwald E. Nina Starr Braunwald: some reflections on the first woman heart surgeon. Ann Thorac Surg 2001; 71 (2 Suppl): S6- S7.

13. Blackmon SH, Carpenter AJ. Nina Starr Braunwald's career, legacy, and awards: results of a survey of the Thoracic Surgery Foundation Award recipients. Ann Thorac Surg 2018; 106: 633- 636. 


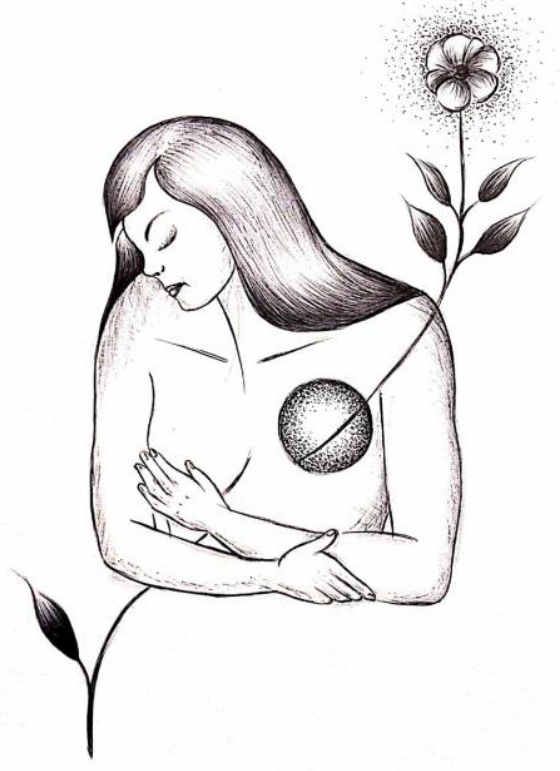

\section{Disease flower}

The transplanted heart becomes an integral part of the recipient. Although a person faces great difficulties in the postoperative period, he has the opportunity to live!

"God didn't promise days without pain, laughter without sorrow, or sun without rain, but He did promise strength for the day, comfort for the tears, and light for the way."

Khrystyna Drapak, Art Club, Student of Bukovinian State Medical University, Chernivtsi, Ukraine 